\title{
Farmer's lung with a high CD4/CD8 ratio lymphocytic alveolitis: A case report
}

\author{
David Badovinac, Barbara Salobir, Marjeta Terčelj \\ Department of Respiratory diseases and Allergies, University Medical Centre Ljubljana, Ljubljana, Slovenia.
}

Correspondence: David Badovinac. Address: Department of Respiratory diseases and Allergies, University Medical Centre Ljubljana, Zaloska 7, 1000 Ljubljana, Slovenia. Email: badovinac.david@gmail.com

Received: January 21, 2015

Accepted: March 5, 2015

Online Published: March 27, 2015

DOI: $10.5430 /$ crim.v2n2p65

URL: http://dx.doi.org/10.5430/crim.v2n2p65

\begin{abstract}
Background: Farmer's lung is one of the most common forms of hypersensitivity pneumonitis (HP). It is a granulomatous inflammatory disease of the pulmonary parenchyma caused by the immune response to inhalatory antigens, mostly actinomycetes or moulds. The diagnostics range from imaging techniques to bronchoalveolar lavage, which demonstrates a typical lymphocytic alveolitis with a low CD4/CD8 ratio in only one third of patients. It is hypothesised that a low $\mathrm{CD} 4 / \mathrm{CD} 8$ ratio predicts a prosperous course of the disease, but a high CD4/CD8 ratio lymphocytic alveolitis has yet to be determined to announce a more severe clinical course.

Case report: This case report presents a patient with farmer's lung, with a high CD4/CD8 ratio lymphocytic alveolitis and the dynamics of her disease in relation to her environment and therapy. There was clinical improvement, even without therapy, each time the patient moved away from the risk home environment and a setback when she returned back home. Eventually, lung fibrosis with pulmonary hypertension developed.

Conclusion: Our case report does not only illustrate a clear etiological correlation between exposure to causative antigens and progression of farmer's lung, but also emphasises the necessity of early recognition and thorough sanitation of patients' living space. Furthermore, a high CD4/CD8 ratio lymphocytic alveolitis, which is not typical for HP, is indicative of a continuous exposure to causative agents, leading to chronical inflammation and thus a worse clinical course of the disease.
\end{abstract}

\section{Keywords}

Hypersensitivity pneumonitis, Lymphocytic alveolitis, High CD4/CD8 ratio, Disease dynamics, Living environment, Sanitation

\section{Introduction}

Hypersensitivity pneumonitis (HP) or extrinsic allergic alveolitis, is a granulomatous inflammatory disease in the pulmonary parenchyma caused by the patient's immune response to various inhalatory antigens to which the organism has been previously sensitized ${ }^{[1]}$. Lung inflammation is caused by a number of exogenous antigens, mostly of organic origin: different animal and plant proteins, fungi, bacteria, chemical substances ${ }^{[2]}$. Diagnostic criteria of the HP range from history of appropriate exposure or reexposure and high titres of specific immunoglobulins G (IgG) antibodies (serum precipitins), typical clinical picture along with imaging techniques such as plain chest radiography and computed tomography, altered pulmonary function tests, bronchoalveolar lavage (BAL) and compatible lung biopsy findings ${ }^{[3]}$. 
BAL demonstrates a typical lymphocytic alveolitis with low CD4/CD8 ratio in only one third of patients with HP, yet, even with the absence of this low ratio and considering the other diagnostic criteria, the diagnosis of HP cannot be ruled out ${ }^{[4]}$. Among different forms of HP, farmer's lung is one of the most common. It usually affects farm workers after inhalation of actinomycetes or moulds in deteriorating hay or grain. The duration and intensity of the antigen exposure determine the clinical picture of the disease, which can be acute, subacute or chronic ${ }^{[1,5,6]}$. After the diagnosis of farmer's lung is made, elimination of exposure to causative antigens presents the most basic and primary therapeutic measure, which can sometimes lead to a spontaneous regression of the disease. In more severe cases, where signs and symptoms of the disease are more intense, corticosteroids are the treatment of choice ${ }^{[6]}$. Unfortunately, sometimes even the optimal pharmacological treatment has little effect on the progression of the disease, which can eventually lead to extensive pulmonary fibrosis. In such cases, continual exposure of patients to causative antigens in their living environment must be considered. A worse clinical course of HP during continuous antigen exposure may present itself with a different kind of inflammation of lung parenchyma than in milder cases. It is hypothesised that a low CD4/CD8 ratio predicts a prosperous course of the disease, but a higher CD4/CD8 ratio lymphocytic alveolitis determines a continuous exposure to causative agents, which leads to chronic form of HP and thus announces a more severe clinical course ${ }^{[7,8]}$. However, this remains to be established, as reports of cases of HP with CD4 alveolitis in Europe have been sporadic ${ }^{[9]}$.

This case report presents a patient with a HP-farmer's lung, in who we managed to prove a lymphocytic alveolitis with a high CD4/CD8 ratio. Considering the dynamics of her disease, with a relapse every time she returned to her home farm with a high burden of causative antigens, we presume that alveolitis with high CD4/CD8 ratio predisposed a more severe course and a worse outcome of the disease. In five years, the patient has developed pulmonary fibrosis with pulmonary hypertension and was eventually put on long-term oxygen treatment (LTOT).

\section{Case report}

\subsection{The case}

Our patient is a 52 years old female who worked on a family farm and lived in an old damp house with mouldy ceilings and walls. She never smoked and had no clinical history of health issues in the past.

In 2004, she was treated for atypical pneumonia. Since then she had mild respiratory tract symptoms with dry cough, occasional headaches and slightly progressive dyspnoea during physical straining. One year later, due to these symptoms, she had demonstrated hypersensitivity to the house mite and received antihistamines. No further examinations were done until 2008, when she was admitted to the hospital due to acute worsening of respiratory insufficiency with dyspnoea at rest, headaches, fever and shivering, myalgia and polyarthralgias. She was experiencing fatigue on minimal physical activity and periodic non-productive cough.

\subsection{Disease dynamics and clinical management}

At first admission to hospital, the patient had dyspnoea with cyanosis and diffuse inspiratory crackles on chest exam. Her laboratory and pulmonary function tests reflected her deteriorated clinical condition (see Table 1). Radiographic imaging with plain chest X-ray demonstrated bilateral interstitial changes with a reticulonodular pattern, located mostly basally and a border normal-sized heart (see Figure 1). High Resolution Computed Tomography (HRCT) presented impairment of the small respiratory pathways accompanied by diffuse "ground glass" interstitial changes (see Figure 2). BAL cytometry demonstrated total cell count of 550 cells $/ \mathrm{mL}$, with $74 \%$ of lymphocytes: lymphocyte T CD3 96\%, CD4 81\%, CD8 14\%. Distinctively high levels of CD4 T-lymphocytes made up the CD4/CD8 index of 5.79. Due to this high CD4/CD8 ratio and consequential suspicion of sarcoidosis, serum angiotensin-convertase (sACE) levels were measured, but were within normal range (see Table 1). Hyperplasia of mucinous cells with partially developed noncaseating granulomas in the epithelium was discovered on lung biopsy and very high titres of specific IgG against certain moulds in patient's home 
environment were found (see Table 2). Taking all these findings into consideration, along with a typical clinical picture and history of exposure to moulds, the diagnosis of farmer's lung was set ${ }^{[3]}$.

Table 1. Dynamics of the disease with different spirometry parameters and values of serum angiotensin converting enzyme (SACE)

\begin{tabular}{llllll}
\hline & $\begin{array}{l}\text { First } \\
\text { hospitalisation } \\
\text { (Aug. 2008) }\end{array}$ & $\begin{array}{l}\text { First } \\
\text { hospitalisation } \\
\text { (Sep. 2008) }\end{array}$ & $\begin{array}{l}\text { Second } \\
\text { hospitalisation } \\
\text { (Nov. 2008) }\end{array}$ & $\begin{array}{l}\text { Second outpatient } \\
\text { check-up } \\
\text { (Nov. 2008) }\end{array}$ & $\begin{array}{l}\text { Third } \\
\text { hospitalisation } \\
\text { (Nov. 2010) }\end{array}$ \\
\hline Vital lung capacity & $65 \%$ & $75 \%$ & $82 \%$ & $73 \%$ & $71 \%$ \\
FEV1 & $77 \%$ & $76 \%$ & $83 \%$ & $88 \%$ & $79 \%$ \\
DLCO $(\%)$ & 38 & $/$ & $/$ & 32 & 36 \\
$\mathrm{pO}_{2}$ without extra & 6.3 & 8.2 & 7.1 & 8.2 & 5.1 \\
oxygen $(\mathrm{kPa})$ & & 0.16 & 0.07 & 0.07 & 0.04 \\
SACE $(\mu \mathrm{kat} / \mathrm{L})$ & 0.08 & & & & \\
\hline
\end{tabular}

Note. Values of vital lung capacity and FEV1 are percentages of the predicted values for standardised population of the same sex, age and height; diffusing capacity (DLCO) values from August and

September 2008 have not been noted.

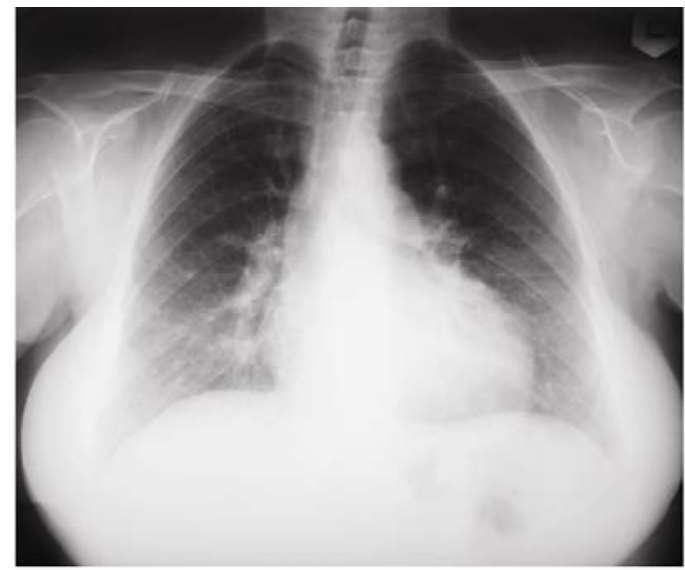

Figure 1. Plain chest radiograph during the first hospitalisation, showing bilateral, mostly basal interstitial changes with a reticulonodular pattern and a border normal-sized heart.

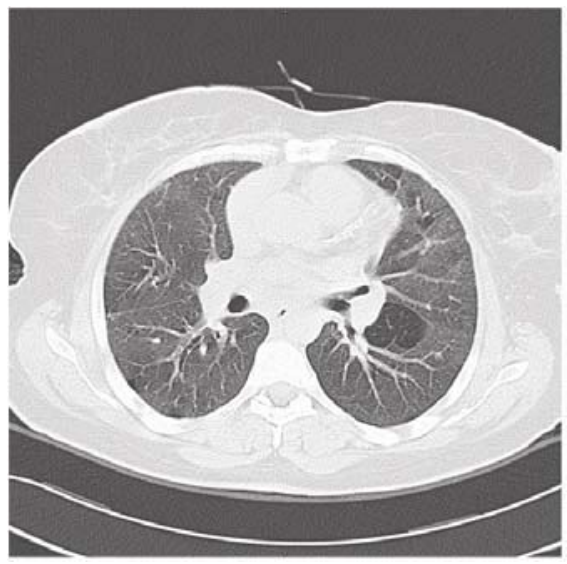

Figure 2. High Resolution Computed Tomography of the chest during the first hospitalisation, showing diffuse »ground glass « interstitial changes in lungs with affected small respiratory pathways.

During diagnostic procedures in the hospital, spontaneous regression of the disease, without any glucocorticoid (GC) therapy, was noted. She experienced relieved breathing and $\mathrm{pO}_{2}$ without adding extra oxygen improved to $8.2 \mathrm{kPa}$ (see Table 1). Nevertheless, due to fairly vigorous alterations on imaging diagnostics and due to low lung diffusion capacity we decided to introduce per os GC treatment (metil-prednisolone $32 \mathrm{mg}$ daily). Considering the epidemiologic anamnesis of patient's home environment, high precipitins to certain mould antigens and a spontaneous clinical regression during her hospitalisation, thorough sanitisation and renovation of her house was advised, along with restriction of any occupation with hay on the family farm.

On check-up, one month later, the respiratory system was clinically stable, thus GC dosage for further treatment was reduced (metil-prednisolone $16 \mathrm{mg}$ daily). After two weeks of this lower GC dosage, there was a clinical setback with aggravation of the acute respiratory insufficiency. Meanwhile, her home was still not renovated and she continued working on her farm. 
She was once again admitted to the hospital in respiratory insufficiency. Her clinical condition gradually improved, respiratory insufficiency disappeared and chest X-ray improved without any changes in therapy (metil-prednisolone 16 $\mathrm{mg}$ daily) during this second hospitalisation. The patient was dismissed on the same lower GC therapy, but this time to her daughter's family in the urban environment, where she had lived until her own house was sanitised and renovated.

On the second outpatient check-up, she denied having notable respiratory symptoms and described her personal condition as good. Imaging techniques still demonstrated certain interstitial changes in lungs, yet less than before. Pulmonary function tests have also partially improved as well as blood oxygenation (see Table 1). All this time, before the check-up, she stayed in the city with her daughter and did not even once visit her farm. Afterwards she did not want to come back for additional check-ups and despite our recommendations, she insisted on living in her own home, although measurements of fungal biomass burden in our patient's home environment proved the house was only partly sanitised.

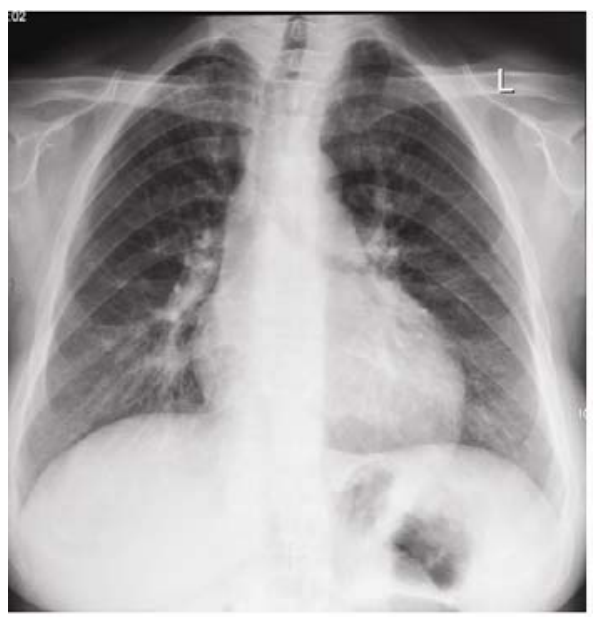

Figure 3. Plain chest radiograph during the third hospitalisation, showing interstitial changes involving the lower lung lobes with distortion of the underlying blood vessels and heart enlargement.

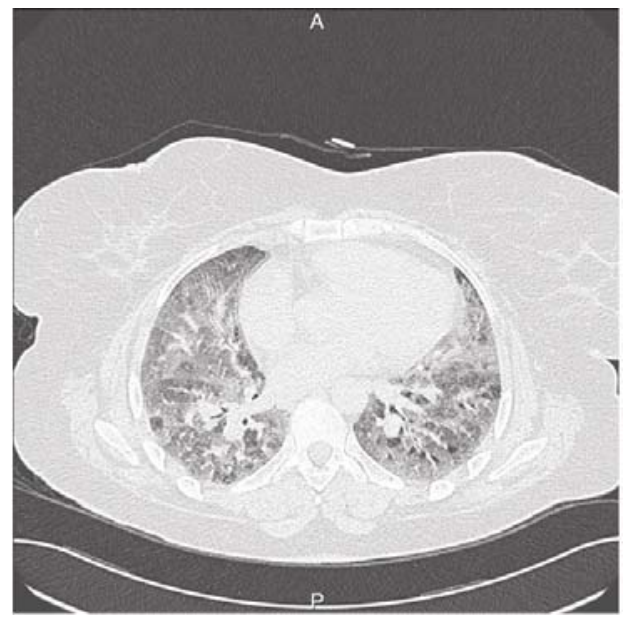

Figure 4. High Resolution Computed Tomography of the chest during the third hospitalisation, showing diffuse interstitial abnormalities in lungs, along with affected small respiratory pathways.

Table 2. Values of serum precipitins against different moulds in the first (during the first hospitalisation) and the second testing (during the third hospitalisation)

\begin{tabular}{lll}
\hline & First hospitalisation & Third hospitalisation \\
\hline $\begin{array}{l}\text { Specific IgG - Gmx6 (Penicillium notatum, } \\
\text { Cladosporium herbarum, Mucor racemosus, }\end{array}$ & $143.00 \mathrm{mg} / \mathrm{L}$ & $70.60 \mathrm{mg} / \mathrm{L}$ \\
$\begin{array}{l}\text { Alternaria aletrnata) } \\
\text { [norm. up to } 10,53 \mathrm{mg} / \mathrm{L}]\end{array}$ & & \\
$\begin{array}{l}\text { Specific IgG }-\mathrm{Gm} 3 \text { (Aspergillus fumigatus) } \\
\text { [norm. up to } 39,00 \mathrm{mg} / \mathrm{L}]\end{array}$ & $146.00 \mathrm{mg} / \mathrm{L}$ & $78.20 \mathrm{mg} / \mathrm{L}$ \\
\hline
\end{tabular}

Two years later, in 2010, she came back due to severe clinical setback with acute respiratory insufficiency. Evident enlargement of pulmonary arteries with enlarged cardiac silhouette was demonstrated on the plain chest radiogram (see Figure 3) and HRCT showed even more vigorous interstitial changes of lungs then two years earlier (see Figure 4). Pulmonary function tests expressed small change, but respiratory insufficiency deteriorated nonetheless (see Table 1). Certain specific IgG to moulds, were again extremely high, yet substantially lower than in 2008 (see Table 2). She had progressing lung fibrosis with pulmonary hypertension. LTOT was introduced to her therapy and yet again, despite our dissuasion, she insisted on returning back to her house. 
We suggested lung transplantation, but under strict condition to move out of her home. Because she refused that option and was unmotivated for any lifestyle changes, lung transplantation was out of question. Up to now, she is still alive, with her clinical condition critical, but stable. She refuses to return for further check-ups and remains on LTOT and GC therapy.

\section{Discussion}

Our patient, who lived in a very old, mouldy house and was working at her family farm, also handling hay, had had slowly progressive respiratory symptoms for four years before the diagnosis of HP was made. Due to a long term exposure to moulds in her living environment, HP has slowly progressed and was already fully developed at the time of diagnosis. Titres of precipitins to agents of farmer's lung were exceedingly high, but the diagnosis of the disease cannot be made strictly on the basis of positive antibodies ${ }^{[10,11]}$. Yet, later on, when the home environment, in which she got ill, was sanitised and renovated (but probably not completely), the values of serum precipitins fell by half and clinically the patient improved.

Cytology of BAL showed moderately higher CD4/CD8 ratio lymphocytic alveolitis, but there were no other diagnostic criteria in favour of suspicion of sarcoidosis or any other disease. CD4/CD8 ratio may be high in both - sarcoidosis and $\mathrm{HP}^{[8,12,13]}$. This kind of alveolitis as has been shown in our patient and is not typical of HP nor sarcoidosis, may well be an indicator of a worse course of the disease during continual antigen exposure in the living or working environment.

Though being typical for HP, lymphocytic alveolitis with a low CD4/CD8 ratio has been shown to be present in only one third of all patients. Whether the patients with a typical clinical picture and atypically higher CD4/CD8 ratio have a different, more serious course of the disease, is not yet fully known. It might be linked to constant antigen exposure in living space as has been proved to be the case in patients with sarcoidosis ${ }^{[14,15]}$. For sarcoidosis, which has long been thought to be an idiopathic disease without an obvious triggering factor, there is lately growing evidence that it is probably linked with inhalation of immunomodulating agents in the fungal cell. In this case, we established that the degree of lung inflammation was closely related to the level of fungal antigens in the patient's living environment; this connection is in sarcoidosis known to be linked with a higher CD4/CD8 ratio. The same might be true for those patients with farmer's lung who have not been proven to have alveolitis with a lower CD4/CD8 ratio, which is otherwise typical of the disease. A higher ratio could be a potential marker of chronic exposure to causative antigens of $\mathrm{HP}{ }^{[8]}$, therefore it should be an indication for more intense environmental studies in search of the source of the disease. Furthermore, higher CD4/CD8 ratio might also indicate a chronic form of $\mathrm{HP}^{[7]}$, which is already known to have a worse outcome.

Perhaps in such cases even a complete elimination of causative antigens fails to bring the wanted improvement ${ }^{[16]}$. During a stay in an environment different from home, there was a significant clinical improvement; even more significant than after returning back home, which was at that time already renovated and sanitised. GC therapy at that time failed to have the same efficiency. Measurements of fungal biomass burden in patient's home environment, by measuring fungal enzyme $\mathrm{N}$-acetyl- $\beta$-D-hexosaminidase (NAHA) activity ${ }^{[14]}$, proved the house was only partly sanitised, but the patient insisted on continuing to live in it. Adequate measures and attempts to eliminate potential disease risk factors help most of the patients with HP to recover and roughly only half of these patients actually develop mild chronic forms of the disease ${ }^{[16,17]}$. Yet, our patient failed to follow this example and soon after returning home her clinical condition deteriorated which gradually lead to development of pulmonary fibrosis, followed by pulmonary hypertension and chronic pulmonary heart disease. Eventually, oxygen therapy throughout the day was necessary.

Long-term exposure to moulds in the living environment results in development of the disease and also in its progression, which, in our case, could not be stopped even with periods of being away from inhalatory antigens in patient's house. Nonetheless, partial remission was detected each time the patient stayed away from home. All of this emphasises the necessity of systematic isolation of the patient with farmer's lung, regardless of the alveolitis type, from the noxious environment even more. Therefore it is obvious that instructions for our patient to permanently leave her home 
environment were crucial for the treatment and recovery from the disease. Failing to do so, the disease has progressed despite the GC therapy.

Our case report of a patient with farmer's lung with high CD4/CD8 ratio demonstrates clear inseparability of adequate medication and simultaneous evacuation from the damaging environment. Despite GC therapy, clinical condition of our patient gradually deteriorated in the insufficiently sanitised home. Similar lack of efficiency of GC treatment on long-term outcome was also indicated in certain researches, which on other hand discovered favourable effects of GC only during acute stages of $\mathrm{HP}^{[5,6]}$. Yet, these researches did not take into consideration the permanent exposure to risk factors in the environment, from which the patient refused to move out.

\section{Conclusion}

This case report of a patient with severe progression of HP under long-term exposure to environmental agents, presented with atypically high CD4/CD8 lymphocytic alveolitis, shows that, besides proper drug therapy, removal of causative risk factors or removal of the patient from such environment is obligatory. Furthermore, this kind of alveolitis, not usual for HP, marks continuous exposure to causative agents and should indicate further environmental studies in search of the source of the disease. Higher CD4/CD8 ratio also denotes chronic form of the disease, therefore, it may well be an indicator of a worse course and outcome of HP.

\section{Reference}

[1] Fink JN, Ortega HG, Reynolds HY, et al. Needs and opportunities for research in hypersensitivity pneumonitis. Am J Respir Crit Care Med. 2005; 171: 792-8. PMid:15657460 http://dx.doi.org/10.1164/rccm.200409-1205WS

[2] Cormier Y, Israël-Assayag E. Pathogenesis of hypersensitivity pneumonitis. In: Wardlaw AJ, Hamid QA, eds. Textbook of Respiratory Cell and Molecular Biology. 1st ed. London: Martin Dunitz Ltd; 2002. 147-58 p.

[3] Schuyler M, Cormier Y. The diagnosis of hypersensitivity pneumonitis. Chest. 1997; 111: 534. http://dx.doi.org/10.1378/chest.111.3.534

[4] Caillaud DM, Vergnon JM, Madroszyk A, et al. Bronchoalveolar lavage in hypersensitivity pneumonitis: a series of 139 patients. Inflamm Allergy Drug Targets. 2012; 11(1): 15-9. PMid:22309080 http://dx.doi.org/10.2174/187152812798889330

[5] Wild LG, Lopez M. Hypersensitivity pneumonitis: a comprehensive review. J Investig Allergol Clin Immunol. 2001; 11(1): 3-15. PMid:11436968

[6] Patel AM, Ryu JH, Reed CE. Hypersensitivity pneumonitis: current concepts and future questions. J Allergy Clin Immunol. 2001 Nov; 108(5): 661-70. PMid:11692086 http://dx.doi.org/10.1067/mai.2001.119570

[7] Barrera L, Mendoza F, Zuñiga J, et al. Functional diversity of T-cell subpopulations in subacute and chronic hypersensitivity pneumonitis. Am J Respir Crit Care Med. 2008 Jan 1; 177(1): 44-55. PMid:17947613 http://dx.doi.org/10.1164/rccm.200701-093OC

[8] Ando M, Konishi K, Yoneda R, et al. Difference in the phenotypes of bronchoalveolar lavage lymphocytes in patients with summer-type hypersensitivity pneumonitis, farmer's lung, ventilation pneumonitis, and bird fancier's lung: report of a nationwide epidemiologic study in Japan. J Allergy Clin Immunol. 1991; 87: 1002-9. http://dx.doi.org/10.1016/0091-6749(91)90423-L

[9] Caillaud DM1, Vergnon JM, Madroszyk A, et al. Bronchoalveolar lavage in hypersensitivity pneumonitis: a series of 139 patients. Inflamm Allergy Drug Targets. 2012 Feb; 11(1): 15-9. PMid:22309080 http://dx.doi.org/10.2174/187152812798889330

[10] Fenoglio CM1, Reboux G, Sudre B, et al. Diagnostic value of serum precipitins to mould antigens in active hypersensitivity pneumonitis. Eur Respir J. 2007 Apr; 29(4): 706-12. Epub 2006 Dec 20. PMid:17182654

http://dx.doi.org/10.1183/09031936.00001006

[11] Mohr LC. Hypersensitivity pneumonitis. Curr Opin Pulm Med. 2004 Sep; 10(5): 401-11. PMid:15316440 http://dx.doi.org/10.1097/01.mcp.0000135675.95674.29

[12] Wahlström J, Berlin M, Lundgren R, et al. Lung and blood T-cell receptor repertoire in extrinsic allergic alveolitis. Eur Respir J. 1997; 10: 772-9. PMid:9150312

[13] Soler P, Nioche S, Valeyre D, et al. Role of mast cells in the pathogenesis of hypersensitivity pneumonitis. Thorax. 1987; 42: 565-72. PMid:3499002 http://dx.doi.org/10.1136/thx.42.8.565 
[14] Terčelj M, Salobir B, Harlander M, et al. Fungal exposure in homes of patients with sarcoidosis - an environmental exposure study. Environ Health. 2011 Jan 20; 10(1): 8. PMid:21251285 http://dx.doi.org/10.1186/1476-069X-10-8

[15] Terčelj M, Salobir B, Zupancic M, et al. Inflammatory markers and pulmonary granuloma infiltration in sarcoidosis. Respirology. 2013 Dec; 24. http://dx.doi.org/10.1111/resp.12199

[16] Cormier Y, Bélanger J. Long-term physiologic outcome after acute farmer's lung. Chest. 1985; 87: 796-800. PMid:3996070 http://dx.doi.org/10.1378/chest.87.6.796

[17] Lalancette M, Carrier G, Laviolette M, et al. Farmer's lung. Long-term outcome and lack of predictive value of bronchoalveolar lavage fibrosing factors. Am Rev Respir Dis. 1993; 148: 216-21. PMid:8317802 http://dx.doi.org/10.1164/ajrccm/148.1.216 